\title{
Evaluation of DNA degradation and establishment of a degradation analysis model for Lepidoptera specimens
}

Yao Xu',2, XueYu Ren', HongBin Wang ${ }^{\star,}$, Mei Wang' \& GuoHong Li'

\section{ABSTRACT}

Millions of museum specimens are integral to biodiversity studies; however, DNA degradation may limit the ability to obtain DNA sequences. In this study, a degradation analysis model for Lepidoptera specimens was established. Based on this model, we revealed the characteristics of DNA fragment distribution caused by external DNA damage factors during specimen preservation. We found that the degree of DNA degradation increased over time; DNA degradation of spread and dried adult specimens was significantly higher than that in the folded and formalin-fixed larval specimens. However, the effects of folding wings on DNA degradation and the effects of the preservation method/stage (formalin-fixed larval vs air-dried adult specimens) were different for different species.

\section{METHOD SUMMARY}

Using one-way analysis of variance and the likelihood ratio test, the differences in DNA fragment distribution between different Lepidopteran specimens were analyzed. Based on the random-breakage model, a degradation analysis model for Lepidoptera specimens was established. Based on this model, this paper reveals the characteristics of DNA fragment distribution caused by external DNA damage factors during specimen preservation.

\section{KEYWORDS}

degradation analysis model $\cdot$ DNA degradation - folding of wings $\cdot$ formalin - Lepidoptera specimens

'Key Laboratory of Forest Protection of China State Forestry Administration, Research Institute of Forest Ecology, Environment \& Protection, Chinese Academy of Forestry, No. 1 Dongxiaofu, Haidian District, Beijing 100091, China; ${ }^{2}$ Department of Entomology, China Agricultural University, Beijing 100193, China; *Author for correspondence: wanghb@caf.ac.cn

BioTechniques 68: 138-147 (March 2020) 10.2144/ btn-2019-0166
The combination of fresh and museum specimens has created incredible potential for the study of evolutionary change [1-4]. Recent studies using these specimens have revealed some remarkable instances of phenotypic or genotypic change over certain timescales in response to strong selective pressures [5-12]. However, low concentrations of extracted DNA and relying on small DNA fragments may limit the ability to obtain DNA sequences from specimens [13-15]. Traditional museums store collections in cool, dark environments to preserve specimens over long periods. However, standard museum conditions for collections are inadequate to completely prevent the degradation of genomic DNA. Not surprisingly, genomic DNA increasingly degrades and often becomes difficult to use in genetic studies $[10,11,13,15]$.

Discussions about the factors that influence DNA degradation will highlight important considerations and guidelines for processing and preserving specimens $[13,14]$. Previous relevant studies have investigated the effects of age on microsatellite amplification success rates and DNA barcode sequencing rates of historic specimens in museum collections [16-19]. However, disparities in preservation methods and other treatments may also lead to variations in DNA degradation. Regarding preservation methods, few studies have compared the degradation rate in formalin-fixed specimens and other types of specimens (such as air-dried specimens or those preserved in alcohol) because of the difficulties associated with DNA extraction from formalin-fixed specimens [20]. In addition, the DNA fragment size distributions in specimens have rarely been directly examined; however, this information could help researchers to design protocols for analyzing historical specimens. In previous studies, the average fragment size was used to evaluate and compare DNA degradation among diverse specimens $[13,21]$. However, the average fragment size might not fully represent the distribution of the most abundant fragment sizes. A regression model showing the DNA fragment size distributions would be more beneficial regarding the provision of direct evidence for primer design $[13,14]$. To our knowledge, this model has not yet been established. Additionally, the previous specimen-based studies have often been limited to certain species and a small number of specimens. Here, we present research on a wide range of species to tackle the challenges associated with previous studies. Lepidoptera is the second-most diverse order of insects and the task for the identification of Lepidopteran insects is difficult and complex [22,23]. The gene sequences of fresh and museum specimens have been heralded as a major new tool for the identification of Lepidopteran insects. Therefore, in this study, Lepidoptera specimens were used to analyze the effects of preservation methods, handling of the wings and storage time on the DNA degradation. Overall, these results may help to guide the processing, storage and selection of specimens for DNA-based studies.

\section{MATERIALS \& METHODS}

Specimen samples

Multiple Lepidoptera specimens were collected between 1957 and 1999 and were stored in forest insect specimen banks at the Chinese Academy of Forestry. All specimens were divided into three groups. The first group, which was used to analyze the DNA degradation rate over time, consisted of all Lymantria dispar specimens (Table 1). The second group, which was used to analyze the differences in DNA degradation between folded specimens and spread specimens, consisted of six species (Table 2). The third group, which 
Table 1. List of Lymantria dispar specimens used in this study.

\begin{tabular}{|l|l|l|l|l|l|}
\hline \multicolumn{2}{l}{ Species } & Collection date & $\begin{array}{l}\text { Storage time } \\
\text { (years) }\end{array}$ & Samples (n) & \multicolumn{2}{l|}{ Average DNA length Standard deviation } \\
\hline L. dispar (spread-dried) & 1957 & 60 & 5 & 210.54 & 6.54 \\
\hline L. dispar (spread-dried) & 1964 & 53 & 4 & 199.00 & 5.97 \\
\hline L. dispar (spread-dried) & 1973 & 44 & 3 & 209.43 & 6.01 \\
\hline L. dispar (spread-dried) & 1979 & 38 & 8 & 215.45 & 5.74 \\
\hline L. dispar (spread-dried) & 1982 & 35 & 7 & 208.92 & 4.63 \\
\hline L. dispar (spread-dried) & 1987 & 30 & 3 & 228.09 & 3.32 \\
\hline L. dispar (folded-dried) & 1987 & 30 & 5 & 230.01 & 3.63 \\
\hline L. dispar (formalin larval) & 1987 & 30 & 5 & 229.26 & 3.92 \\
\hline L. dispar (spread-dried) & 1993 & 24 & 6 & 234.12 & 4.50 \\
\hline L. dispar (spread-dried) & 1996 & 21 & 6 & 260.84 & 5.82 \\
\hline L. dispar (spread-dried) & 1999 & 18 & 3 & 268.47 & 5.39 \\
\hline
\end{tabular}

was used to evaluate the differences in DNA degradation between air-dried adult specimens and formalin-preserved larval specimens, consisted of approximately three to nine specimens of each species (Table 3). Information on the processing of specimens prior to preservation is provided in Supplementary Appendix 1.

\section{DNA extraction}

All specimens were washed in sterile distilled water to remove surface contaminants and excess formalin and the specimens were then air-dried. For the dried specimens, the tissue was lysed and the lysate was purified using the E.Z.N.A. ${ }^{\text {IM }}$ Insect DNA Kit (Omega), following the manufacturer's protocol, modified by incubation at $60^{\circ} \mathrm{C}$ for $2 \mathrm{~h}$. This protocol began with rinsing the specimens in xylene, followed by serial treatment with ethanol to break the protein-DNA crosslinkages caused by formalin exposure. Specimens were then left to dry at room temperature $\left(22^{\circ} \mathrm{C}\right)$ for $2 \mathrm{~h}$. After the drying process, a part of the larvae was ground in liquid nitrogen. The E.Z.N.A. Insect DNA Kit (Omega) was then used to extract DNA following the manufacturer's protocol, modified by incubation at $60^{\circ} \mathrm{C}$ for $2 \mathrm{~h}$. All extracted DNA was stored in elution buffer at $-20^{\circ} \mathrm{C}$. To reduce the effects of differences in the extracted genomic DNA concentration on the DNA degradation analysis, ground tissue $(40 \mathrm{mg}$ ) was used for DNA extraction. After DNA extraction, a DS-11 Spectrophotometer (DeNovix, DE, USA) was used to measure the DNA concentration and absorbance ratio $(260 / 280 \mathrm{~nm})$.

\section{DNA fragment analysis by automatic} capillary electrophoresis

Each DNA extract $(20 \mu \mathrm{l})$ was analyzed on a Qsep100 Fully Automated Nucleic Acid and Protein Analysis System (Bioptic, Taipei, TW, China) following the manufacturer's protocol. Digital data, gel-image format and capillary electropherograms were exported by the Q-Analyzer software (Bioptic). For

Table 2. The spread and folded specimens used in this study.

\begin{tabular}{|l|l|l|l|}
\hline Species & Treatment of wings & Collection date & Samples (n) \\
\hline Gastropacha populifolia & Spread & June 1957 & 4 \\
\hline & Folded & & 8 \\
\hline Pterostoma sinicun & Spread & April 1957 & 3 \\
\hline & Folded & & 3 \\
\hline Dendrolimus tabulaeformis & Spread & July 1957 & 3 \\
\hline & Folded & & 5 \\
\hline Semiothisa cinerearia & Spread & August 1957 & 5 \\
\hline & Folded & & 5 \\
\hline Leucoma candida & Spread & June 1957 & 5 \\
\hline & Folded & & 5 \\
\hline Spilosoma niveus & Spread & May 1957 & 5 \\
\hline & Folded & & 5 \\
\hline
\end{tabular}


Table 3. The dried and formalin specimens used in this study.

\begin{tabular}{|l|l|l|l|l|}
\hline Species & Stage & Preservation method & Collection date & Samples (n) \\
\hline Dendrolimus punctatus & Larva & Formalin & May 1957 & 9 \\
\hline & Adult & Dry & & 3 \\
\hline Culcula panterinaria & Larva & Formalin & July 1957 & 4 \\
\hline & Adult & Dry & & 5 \\
\hline Dictyoploca japonica & Larva & Formalin & August 1957 & 5 \\
\hline & Adult & Dry & & 3 \\
\hline Ourapteryx nivea & Larva & Formalin & July 1957 & 5 \\
\hline & Adult & Dry & & 5 \\
\hline Clostera anastomosis & Larva & Formalin & July 1957 & 4 \\
\hline & Adult & Dry & & 5 \\
\hline Spilarctia subcarnea & Larva & Formalin & July 1957 & 5 \\
\hline & Adult & Dry & & \\
\hline Dendrolimus tabulaeformis & Larva & Formalin & July 1957 & 6 \\
\hline & Adult & Dry & & 3 \\
\hline Percnia giraffata & Larva & Formalin & August 1957 & 4 \\
\hline & Adult & Dry & & 4 \\
\hline
\end{tabular}

each specimen, we obtained a capillary electropherogram, relative fluorescence intensity migration time plot, proportions of DNA fragments and their distribution and average fragment length. A fragment distribution of 20-900 bp was observed for these specimens as well. For all specimens, the percentage of DNA fragments out of the total DNA was calculated for each set of 20 fragment sizes (20-40, 40-60 and so on to $880-900 \mathrm{bp})$, comprising 44 classes. An example of the raw DNA fragment size data is shown in Figure 1 for an $L$. dispar specimen obtained in 1957. In the following analysis, the DNA fragments in classes 1-44 are represented by numbers $1-44$, respectively.

\section{Statistical analysis of the degree of DNA} fragmentation

The likelihood ratio (LR) test was used to analyze whether a significant difference in DNA fragmentation exists between $L$. dispar specimens collected in different years. The LR test was performed according to the methods used in a previous study [24] using SPSS software version 18.0. Moreover, we obtained fitted curves of DNA fragment distribution for each $L$. dispar specimen. Using these fitted curves, we visually displayed and compared the differences in the DNA fragment distribution for each specimen. To produce each fitted curve, we first specified the DNA fragment size class (from 1 to 44 ) as the $x$-axis variable and the proportion of DNA fragments in each class (out of the total DNA) was used as the $y$-axis variable. These data were then imported into Origin 9.5 to obtain a scatter plot of the DNA fragment distribution. Finally, based on the scatter plot, we performed a variety of nonlinear fitting procedures to obtain the curve with the best fit (with the highest coefficient of determination, $R^{2}$ ).

Similarly, the LR test could be used to determine whether differences occurred in the distribution of DNA fragments between spread and folded specimens and between air-dried adult specimens and formalinfixed larval specimens because, for each species, there were only two groups to compare. In addition, to visually display and compare the proportions of DNA fragments between spread and folded specimens and between air-dried adult specimens and formalin-fixed larval specimens, stacked area charts were drawn for some species using Origin 9.5. We divided the 44 classes into four groups (A, B, C and D). Group A included DNA fragments of the first to eighth classes, group B included DNA fragments of the ninth to 17th classes, group $\mathrm{C}$ included DNA fragments of the 18th to 26th classes and group $D$ included DNA fragments of the 27 th to 44 th classes. Thereafter, the proportions associated with these four groups were calculated separately.

\section{Random-breakage model for DNA}

\section{fragment size distributions}

The random-breakage model was established in 1991 by Cook and Mortimer to describe pulsed-field gel electrophoresis and Southern hybridization experiments as well as to analyze the DNA fragment size distributions formed by DNA double-strand breaks induced by ionizing radiation [25]. According to the data obtained in the pulsedfield electrophoresis experiments, the DNA fragment distribution can be obtained using the following formula:

$$
I_{n(x)}=\frac{u}{S}\left(2+u-\frac{u x}{S}\right) \cdot \exp \left(-\frac{u x}{S}\right)
$$

\section{(Equation 1)}

$I_{n(x)}$ : proportion of fragments of length $x$ $x$ : length of fragment

$S$ : initial length of DNA

$u$ : average number of double-strand breaks per DNA 


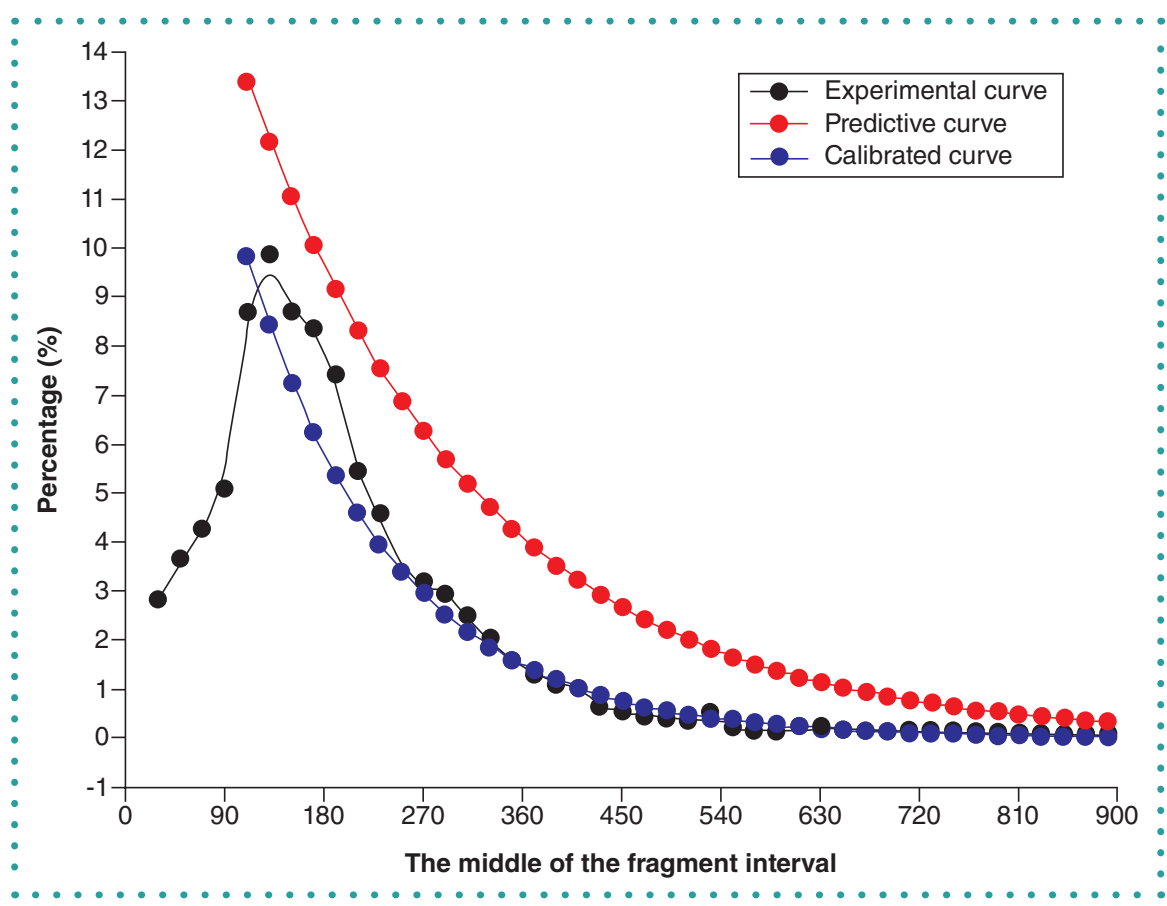

Figure 1. DNA fragment size distribution for a Lymantria dispar (gypsy moth) specimen obtained in 1957. The black curve represents the actual data obtained in this study. The red curve was obtained based on the DNA degradation model for specimens. (Equation 3 ). The blue curve was obtained based on the calibrated DNA degradation model (Equation 4).

The average number of double-strand breaks per DNA (u) can be calculated using the following formula [25]:

$u=\frac{S}{x_{a}}$

(Equation 2)

$x_{\mathrm{a}}$ : average length of all DNA fragments in each specimen

Equation 1 could be immediately used to determine the percentage of each fragment in the specimens. However, we only obtained the percentage of each set of 20 fragment sizes out of the total DNA. Therefore, we established Equation 3 (defining $x$ as the middle fragment length value in each class rather than the length of each fragment) to express the DNA fragment distribution in the specimens:

$$
\begin{gathered}
I_{n(x)}=\frac{u}{S}\left(2+u-\frac{u x}{S}\right) \cdot \exp \left(-\frac{u x}{S}\right) \\
u=\frac{S}{x_{a}}
\end{gathered}
$$

(Equation 3)

$I_{n(x)}$ : proportion of fragments in each class $x$ : middle fragment length value in each set of fragments

$x_{a}$ : average length of all fragments in each specimen

$S$ : initial length of DNA (1 Mbp)

$u$ : average number of double-strand breaks per DNA

We assumed that the initial DNA fragment length was $1 \mathrm{Mbp}$ [13], as the initial DNA fragment lengths were not obtained in this study. Therefore, after the $x$ and $S$ values in Equation 3 were determined, the percentage distribution of DNA fragments was only related to 'the average number of double-strand breaks per DNA (u)', which represents the DNA degradation rate. The $x_{a}$ values (the average fragment length of all DNA fragments) were obtained for each sample based on our experimental data and they were substituted into Equation 3 to obtain the average number of double-strand breaks per DNA $(u)$ for each sample.

\section{Calibration of DNA fragment distribution model for specimens}

The $u$ and $x$ values of each sample were substituted into Equation 3 to obtain the DNA fragment distribution curve predicted by the DNA degradation model. For these specimens, the DNA fragment distribution curve obtained from our experimental results was consistent with that predicted curve by the DNA degradation model when the middle fragment length value was $>110$ bp (DNA fragment classes $5-44$ ) (Figure 1). However, when the middle fragment length value was $\leq 110$ (DNA fragment classes 1-4), the experimental curves (obtained from our experimental results) and predicted curves (based on the degradation model) were completely inconsistent (Figure 1). In fact, regarding the experimental results, only the large fragment classes may contain more genetic information. Therefore, it was more meaningful to discuss the influence of various factors on the percentage distribution of the large DNA fragments. Therefore, in this study, we only analyzed the influence of various factors on the percentage distribution of large DNA fragments (DNA fragment classes 5-44) in the specimens. In summary, the model (Equation 3) can be used to approximately predict the percentage of DNA fragments in each class when the middle fragment length value was $>110 \mathrm{bp}$.

Because there was a deviation between experimental curves and predicted curves, we calibrated the DNA degradation model (Equation 3). As the percentage of DNA fragments in each class (regarding DNA fragment classes 5-44) predicted by DNA degradation model tended to be higher than the actual experimental percentage, we attempted to change the exponent of the power function, as shown in Equation 4:

$$
\begin{gathered}
I_{n(x)}=\frac{u}{S}\left(2+u-\frac{u x}{S}\right) \cdot \exp \left(-z \frac{u x}{S}\right) \\
u=\frac{S}{x_{a}}
\end{gathered}
$$

(Equation 4)

$I_{n(x)}$ : proportion of fragments in each class $x$ : middle fragment length value in each set of fragments

$x_{a}$ : average length of all fragments in each specimen

$S$ : initial length of DNA (1 Mbp)

$u$ : average number of double-strand breaks per DNA

$z$ : 'calibration index' 
The $z$ value (the 'calibration index') is a constant that represents the deviation from the random-breakage model and the calibrated DNA degradation model, such as $1.000,1.001$... Using a range of potential $z$ values, we entered each $z$ value along with the $x$ value, $u$ value and $S$ value into Equation 4 for each specimen. Then, the DNA fragment distribution curves predicted by Equation 4 were obtained. The $z$ value for each specimen was selected based on the mean relative error (MRE) (Equation 5) and the root-mean-square error (RMSE) (Equation 6) between experimental curves (obtained in this study) and predicted curves (obtained from Equation 4), that is, on the basis of having the lowest MRE and RMSE. Lower $z$ values indicate that the DNA fragment distribution in a specimen is more statistically random.

$M R E=\frac{1}{n} \sum_{i=1}^{n} \frac{\left|\hat{Q}_{i}-Q_{i}\right|}{Q_{i}} \times 100 \%$

(Equation 5)

$R M S E=\sqrt{\frac{\sum_{i=1}^{n} d_{i}}{n-1}}$

(Equation 6)

$\hat{Q}_{i}$ : predicted percentage of DNA fragments according to Equation 4

$Q_{i}$ : actual percentage of DNA fragments

$n$ : number of measurements

$d_{i}$ : deviations of predicted percentage from actual percentage

Finally, a DNA degradation model (Equation 4) for specimens was constructed. The DNA degradation model can be changed by adjusting the $u$ value (the average number of double-strand breaks per DNA) and $z$ value (the 'calibration index'). Therefore, the average number of double-strand breaks ( $u$ value) and calibration index ( $z$ value) for all samples were calculated. To determine whether the $u$ or $z$ values were significantly affected by the storage time, one-way Analysis of Variance (ANOVA) was used to analyze whether there was a significant difference between $u$ values or between $z$ values among the L. dispar specimens collected from 1957 to 1999. In the one-way ANOVA, all $u$ or $z$ values were standardized according to the following formula:

$y=\left(x_{i}-\bar{x}\right) / \sigma$

(Equation 7)

$x_{i}: u$ or $z$ values, $\bar{x}:$ mean of all $u$ or $z$ values $\sigma$ : standard deviation of all $u$ or $z$ values.

Thereafter, we used the least significant difference and the Tukey's tests as post hoc tests in SPSS 18.0 software. A p-value $<0.05$ was considered statistically significant.

When the $u$ or $z$ values were significantly affected by the storage time, we had planned to perform a curve correlation analysis regarding the association between storage time and the $u$ or $z$ value using SPSS 18.0. When performing the curve correlation analysis, several models (linear, logarithmic, quadratic, power, cubic function, etc.), which were all provided by SPSS 18.0, were assessed. The storage times were substituted into these models to obtain the dependent variable (i.e., the predicted $u$ or $z$ value). Next, the MRE (based on Equation 5, with $\hat{Q}_{i}$ being the predicted $u$ or $z$ value and $Q_{i}$ being the actual $u$ or $z$ value) and RMSE (based on Equation 6, with $\hat{Q}_{i}$ being the predicted $u$ or $z$ value and $Q_{i}$ being the actual $u$ or $z$ value) between the predicted and actual values were calculated. Finally, the model with the best set of values (high $\mathrm{R}^{2}$ and low MAE and RMSE) was selected as the final model showing the relationship between storage time and the $u$ or $z$ value.

For the spread and folded specimens, the percentages of fragments in each class (regarding DNA fragment classes 5-44) were higher for the folded specimens (Figure 2). In the calibrated DNA degradation model (Equation 4), the $u$ and $z$ values determined the percentage distribution curves of DNA fragments. Therefore, we explored the effect of wing treatment on DNA degradation based on the ratio of the $u$ values and the ratio of the $z$ values for the spread and folded specimens. To show whether the effects of wing treatment on the DNA degradation were consistent for different species, one-way ANOVA was used to determine whether there were significant differences between the ratio of the $u$ values for different species or between the ratio of the $z$ values for different species. Similarly, based on the ratio of the $u$ values and the ratio of the $z$ values for formalin-fixed larval and air-dried adult specimens, we explored the effect of different preservation methods on the DNA degradation (Figure 3). One-way ANOVA was used to determine whether there were significant differences between the ratio of the $u$ values for different species or between the ratio of the $z$ values for different species. In the one-way ANOVA, the ratios of $u$ or $z$ values were standardized according to the following formula:

$z=\left(x_{i}-\bar{x}\right) / \sigma$

(Equation 8)

$x_{i}$ : ratio of $u$ or $z$ values, $\bar{x}$ : mean of all ratios of $u$ or $z$ values, $\sigma$ : standard deviation of all ratios of $u$ or $z$ values. We used the least significant different and Tukey's tests as post hoc tests in SPSS 18.0 software. A p-value $<0.05$ was considered statistically significant.

\section{RESULTS \& DISCUSSION}

Differences in DNA fragment distri-

bution between specimens

DNA fragment distributions of all samples were detected. First, using LR tests, extremely significant differences in DNA fragment distributions were observed between $L$. dispar specimens collected in different years (LR: $d f=8 ; p<0.01$ ). Furthermore, to visually compare the differences in the distributions of large DNA fragments (>100 bp), the curves were fitted for $L$. dispar specimens collected in different years, as shown in Figure 4. The fitted curves were obviously inconsistent; as the storage time increased, the percentage of large DNA fragments in the specimen decreased.

However, previous research demonstrated that there was no significant association between storage time and DNA degradation [26-28]. The degree of DNA degradation in dried specimens was mainly related to the time from death to complete dryness of dried specimens [26-28]. We speculated that the differences in specimen storage times may have led to the inconsistency between our conclusions and previous research results. In the previous research, specimens with short storage times were mainly used $[27,29,30]$. For example, Zhang et al. used dried specimens stored from 4 to 18 years to analyze the effect of storage time on DNA extraction concentration and random amplified 


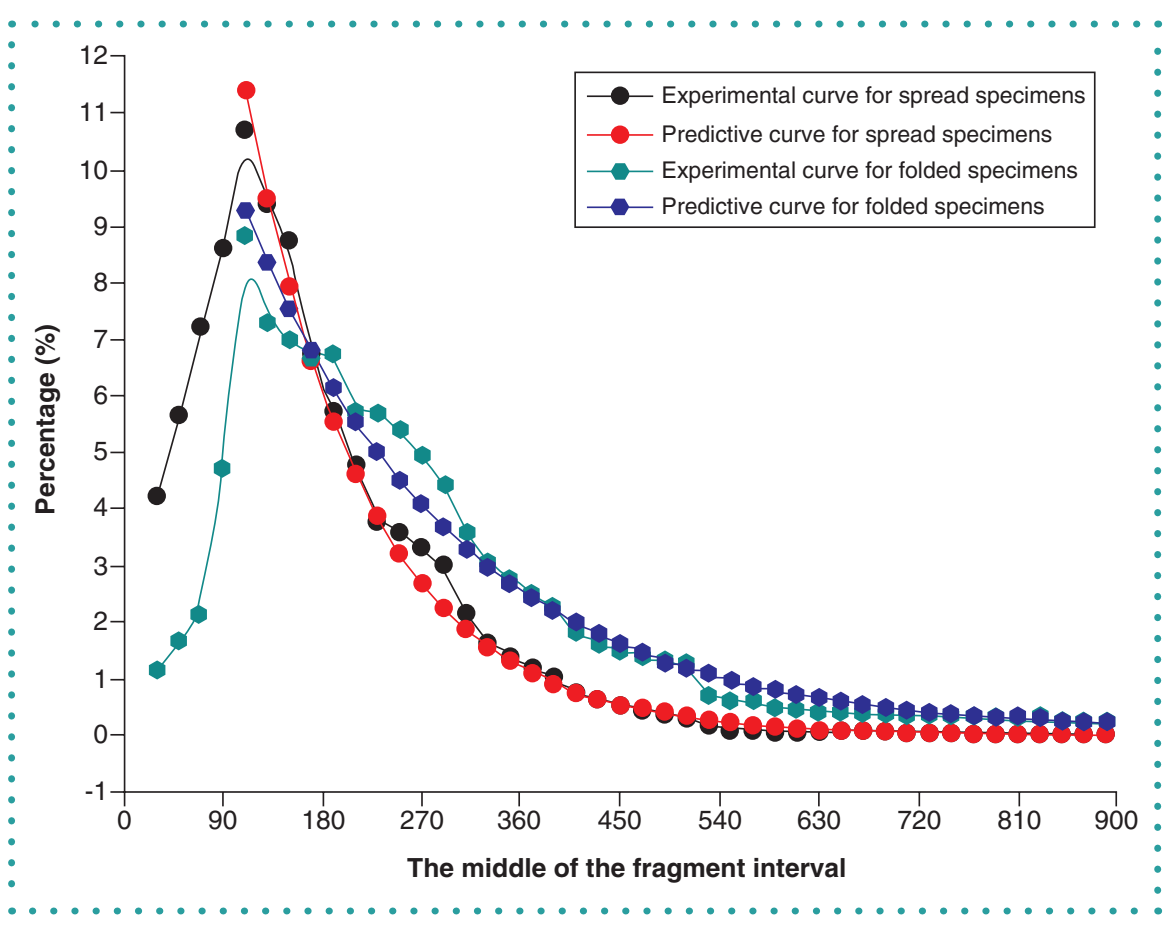

Figure 2. DNA fragment distribution for folded and spread Dendrolimus tabulaeformis specimens. The predicted distribution curves were obtained according to the calibrated DNA degradation model (Equation 4) for the folded and spread D. tabulaeformis specimens.

polymorphic DNA (RAPD)-PCR amplification [31]. When a fresh sample is made into a specimen, the metabolic activity in the cells will gradually stop, the cellular

DNA repair enzymes are then no longer being regulated and the DNA begins to degrade (which can involve DNA-degrading enzymes acting on random segments of

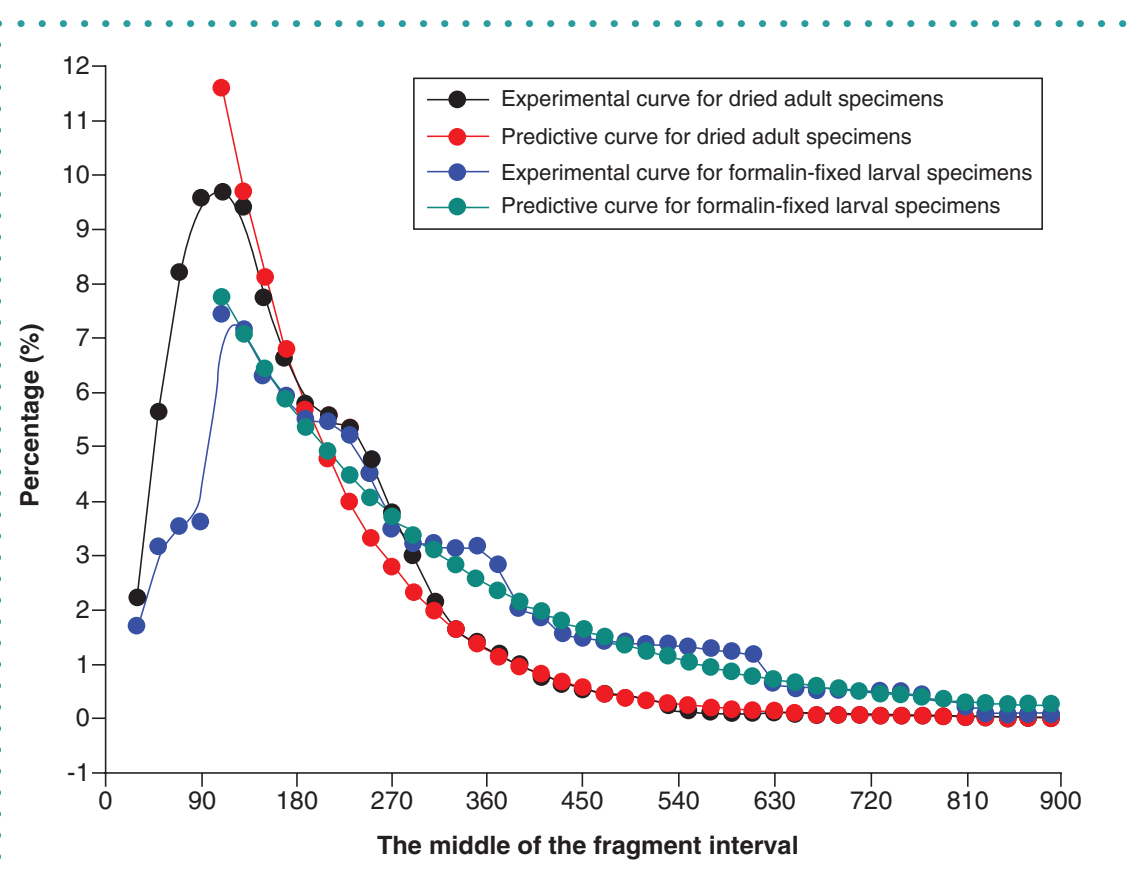

Figure 3. DNA fragment distribution for air-dried adults and formalin-fixed larval Dendrolimus tabulaeformis specimens. The predicted distribution curves were obtained according to the calibrated DNA degradation model (Equation 4) for air-dried adults and formalin-fixed larval D. tabulaeformis specimens.
DNA). However, after the specimen has been stored for a certain period of time, the water in the cells is gradually lost, resulting in inactivation of the DNA-degrading enzymes, so the DNA degradation in the cells will gradually stop. Therefore, the time from death to complete dryness is a crucial determinant of the degree of DNA degradation in specimens $[27,28]$. There was no association between the storage time and the degree of DNA degradation in specimens. The DNA degradation in the air-dried specimens with shorter storage times was mainly related to the time from death to complete drying. In this study, specimens collected from 1957 to 1999 (all >18 years ago) were used to analyze the effect of storage time on DNA degradation. After the specimen has been stored for a sufficient period of time (e.g., >18 years), the environment in the museums, such as the humidity and temperature, will also affect the DNA degradation in the specimens. Thus, in our study, there was a positive association between the storage time and the degree of DNA degradation. In addition to being degraded by DNA-degrading enzymes in the cells, other factors in the museum may also contribute to intracellular DNA degradation. Therefore, for specimens with lengthy storage times (e.g., >18 years), the degree of DNA degradation is not only related to the time from death to complete dryness, but also to the duration during which the specimen is affected by the external environment. Therefore, it is difficult to obtain the gene sequence from the long-preserved specimens. The methodologies, such as next generation sequencing, can be used to carry out these studies with success and relatively good results [29-34].

We then performed the LR tests on two types of specimens of six species: spread and folded specimens. The results for each species showed extremely significant differences in the DNA fragment distributions between the spread and folded specimens (LR: $d f=1 ; p<0.01)$. Additionally, a grouped stacked area chart was produced to directly visualize the DNA fragment distribution in the specimens (Figure 5). Comparison of the proportion of DNA fragments in classes 1-8 (group A) showed a marked increase for the spread specimens compared with the folded specimens (Figure 5). The proportions of DNA fragments in classes 9-17 (group B), 


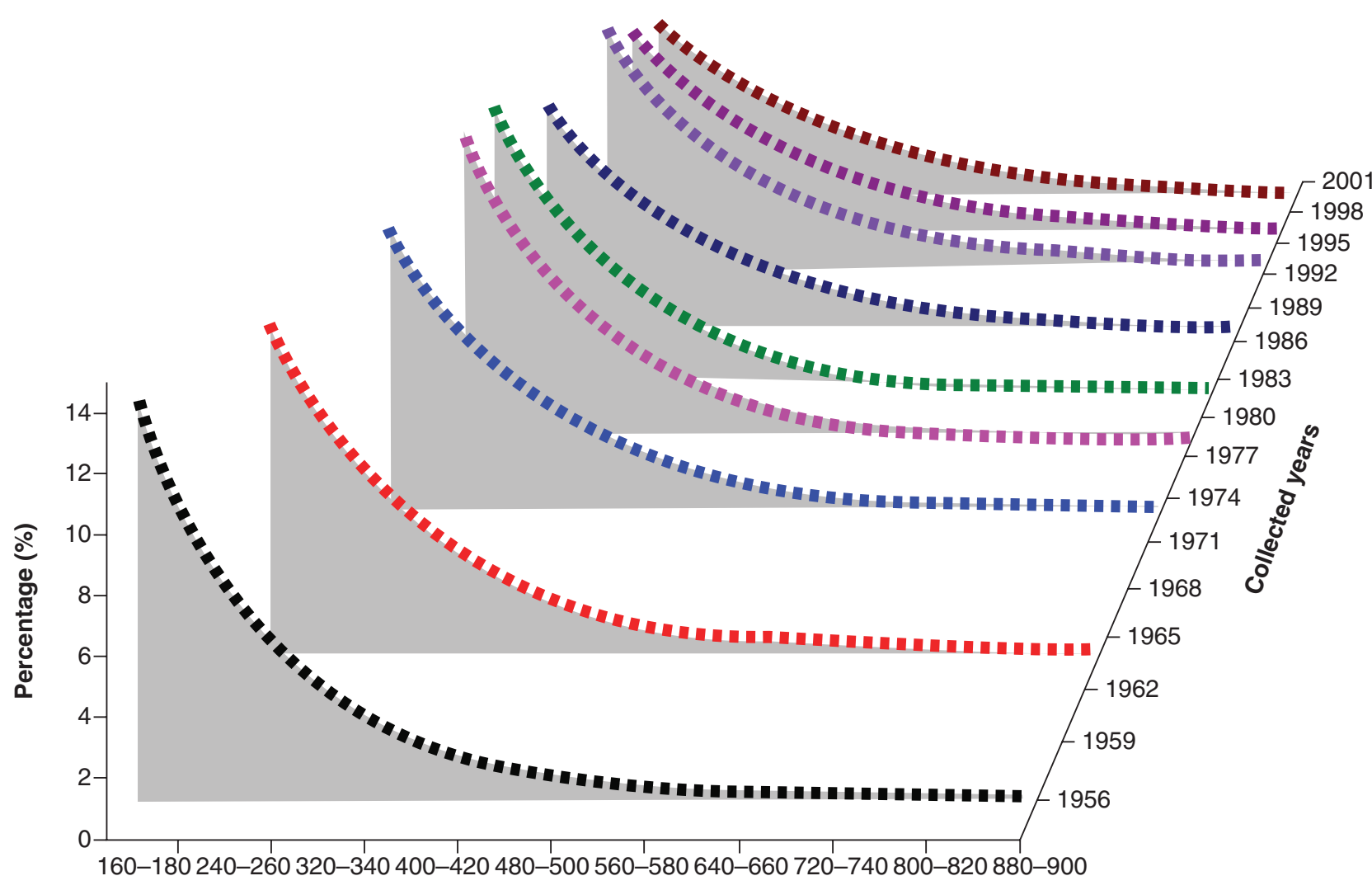

The length of DNA fragments

Figure 4. Comparison of the DNA fragment distribution for Lymantria dispar (gypsy moth) specimens with different storage times.

18-26 (group C) and 27-44 (group D) were markedly lower for the spread specimens than the folded specimens (Figure 5). These observations clearly showed that the degree of DNA degradation in the spread specimens was higher than that of the folded specimens. This may be related to the use of moisture to relax the spread specimens. As reported in previous research, the time from death to complete dryness is a crucial determinant of the degree of DNA degradation in specimens $[27,28,33,35]$. After the poisoned samples (not completely dried) were brought back to the laboratory, the folded specimens continued to be dried to reduce the moisture and retention time of the cellular moisture. In contrast, the spread specimens relaxed with moisture had increased cellular moisture and retention time of cellular moisture, so intracellular DNA self-degradation occurred for longer than in the folded specimens. Therefore, the degree of DNA degradation of the folded specimens was lower than that of the spread specimens.

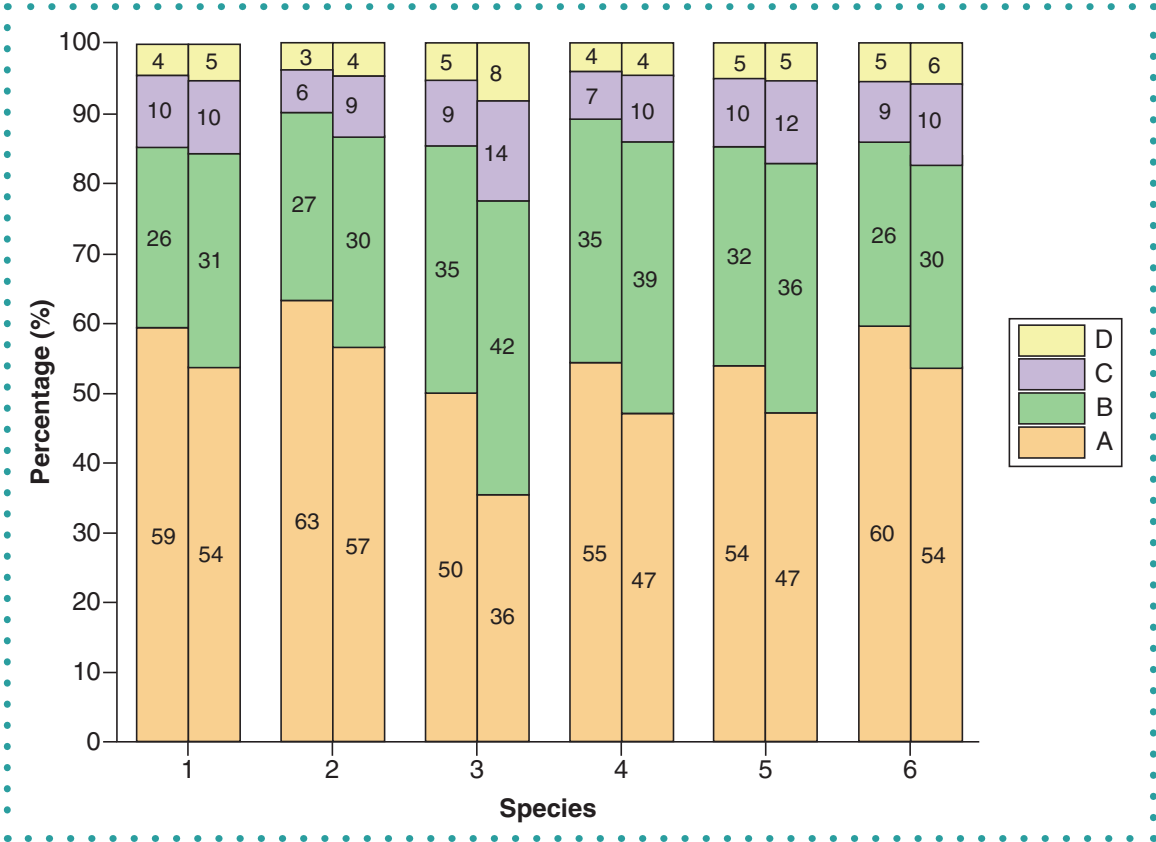

Figure 5. Comparison of the DNA fragment distributions between folded and spread specimens. DNA fragment size distribution in a combined manner for six species. The distributions for folded specimens are shown on the right and the distributions for spread specimens are on the left. Note the differences in the proportion of fragments in each size class for the two types of specimens. Species are arranged in the following order: Pterostoma sinicun, Gastropacha populifolia, Dendrolimus tabulaeformis, Leucoma candida, Spilosoma niveus and Salix cinerearia. 


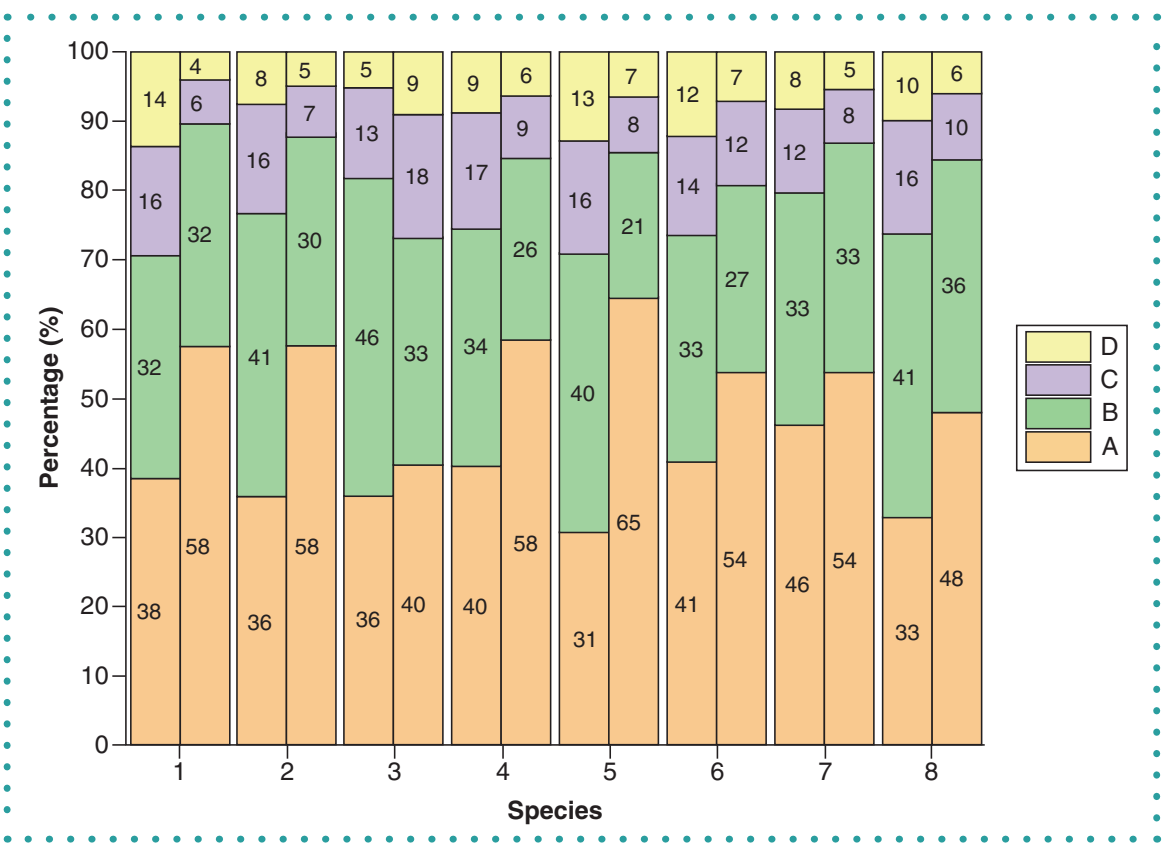

Figure 6. Comparison of the DNA fragment size distributions between air-dried adults and formalinfixed larval specimens. DNA fragment size distribution in a combined manner for eight species. The distributions for formalin-fixed specimens are shown on the left and the distributions for air-dried specimens are on the right. Note the differences in the proportion of fragments in each size class for the two types of specimens. Species are arranged in the following order: Dendrolimus punctatus, Clostera anastomosis, Spilarctia subcarnea, Culcula panterinaria, Percnia giraffata, Ourapteryx nivea, Dictyoploca japonica and Dendrolimus tabulaeformis.

For each species, there were extremely significant differences in the DNA fragment distributions between air-dried adult specimens and formalin-fixed larval specimens $(\mathrm{LR}: \mathrm{df}=1 ; \mathrm{p}<0.01)$. A grouped stacked area chart was produced to directly visualize the DNA fragment distributions in the specimens (Figure 6). The proportion of small DNA fragments (in classes 1-8 [group A]) was higher in air-dried adults than in formalin-fixed larvae (Figure 6). In contrast, obvious increases in the proportions of the large DNA fragments were observed for the formalin-fixed larvae (Figure 6). This may be related to the handling of the air-dried adult specimens prior to storage. The air-dried specimens were relaxed with moisture before storage, so the specimens retained water and the cellular DNA degradation enzymes continued to degrade the DNA. High ambient humidity in the museum may also have resulted in increased water content in the air-dried specimens and increased DNA degradation. Regarding the formalinfixed larval specimens, in the presence of oxygen, the formaldehyde in the formalin is oxidized to formic acid, which reacts with the specimen DNA; the DNA becomes methylated, the diphosphate bond in the DNA strand is cleaved and then crosslinking of nucleic acids and proteins occurs [26]. To reduce the contact between the formalin and the air when a specimen is preserved in formalin, parafilm is often wound around the mouth of the bottle. This prevents oxidation of formaldehyde to formic acid and reduces DNA damage. Despite the fact that the degree of DNA fragmentation was more severe for air-dried adult specimens than for formalin-fixed larval specimens, the latter are not generally recommended for any kind of downstream analysis because of the presence of many PCR inhibitors in the samples [36].

\section{Relationship between specimen storage time \& DNA degradation}

Based on the random-breakage model, a degradation analysis model for Lepidoptera specimens was established (Equation 4). For each sample, we can obtain a predicted standard curve based on this model. Taking the DNA fragment distribution of an L. dispar specimen collected in 1957 as an example, we compared the curves predicted by the DNA degradation model (Equation 3), the curve predicted by the calibrated DNA degradation model (Equation 4) and the curve based on our experimental results, as shown in Figure 1.

There were significant differences in the $u$ values of the $L$. dispar specimens obtained from 1957 to 1999 (ANOVA: df = 8; $F=8.441 ; p<0.01)$, indicating that the $u$ values were significantly affected by the storage time. DNA degradation was significantly affected by the storage time because $u$ values can represent the DNA degradation rate. Thereafter, a curve correlation analysis

Table 4. Model summaries and parameter estimates for u values.

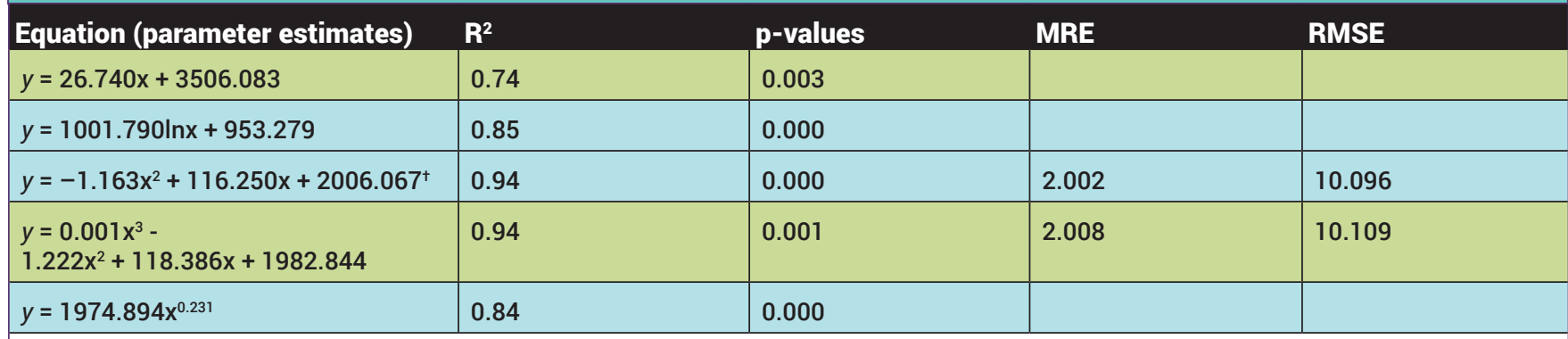

$y$ is the $u$ value and $x$ is the storage time. Only a few models with high coefficient of determination $\left(R^{2}\right)$ values are shown.

${ }^{\dagger}$ This quadratic equation was selected to describe the association between storage time and $u$ value.

MRE: Mean relative error; RMSE: Root-mean-square error. 
was performed regarding the association between storage time and $u$ value in SPSS 18.0 (the $u$ values of all specimens with the same storage time were averaged; Supplementary Table 1). For the curve fitting procedures, parameter estimates for the curve equations and the test statistics of the sample data were shown in Table 4. For both the fitted quadratic and cubic curve equations, the $R^{2}$ value was 0.94 and the models were also both significant. The MRE and RMSE were lower for the quadratic compared with the cubic curve equation (Table 4). Therefore, the quadratic curve equation below (Equation 9) was used to describe the association between storage time and $u$ value.

$u=-1.163 x_{1}^{2}+116.25 x_{1}+2006.067$

(Equation 9)

$x_{1}$ : storage time

In contrast, no significant differences were observed in the $z$ values for $L$. dispar specimens obtained from 1957 to 1999 (ANOVA: $\mathrm{df}=8 ; \mathrm{F}=1.058 ; \mathrm{p}=0.413$ ). This indicated that the deviations between the distribution curves predicted by the calibrated DNA degradation model (Equation 4) and the distribution curves obtained based on the random-breakage model were relatively stable, with no significant association between storage time and the deviations. Therefore, for $L$. dispar specimens with different storage times, the $z$ value in Equation 4 can be replaced by the average of all $z$ values (Supplementary Table 1 ) $(z=1.556)$. Finally, the relationship between storage time and the percentage distribution of DNA fragments can be obtained using the following equation:

$I_{n(x)}=\frac{u}{S}\left(2+u-\frac{u x}{S}\right) \cdot \exp \left(-1.556 \frac{u x}{S}\right)$ $u=-1.163 x_{1}^{2}+116.25 x_{1}+2006.067$

\section{(Equation 10)}

$I_{n(x)}$ : proportion of fragments in each class

$x$ : middle fragment length value in each set of fragments

$x_{r}$ : storage time

$S$ : initial length of DNA (1 Mbp)

$u$ : average number of double-strand breaks per DNA
Relationship between the specimen treatment processes \& DNA degradation For each species, we calculated $u$ values, $z$ values, the ratio of $u$ values and the ratio of $z$ values for the folded and spread specimens (Supplementary Tables 2-4). The $u$ and $z$ values of folded specimens were smaller than those of the spread specimens (Supplementary Table 4). This indicated that the average number of double-strand breaks per DNA of the folded specimens was lower than that of the spread specimens and the percentage distribution of the DNA fragments was closer to that indicated by the random-breakage model. In addition, there were extremely significant differences in the ratio of the $u$ values (for the folded specimens compared with the spread specimens) between different species (ANOVA: $\mathrm{df}=5 ; \mathrm{F}=12.508 ; p<0.01$ ). Similarly, extremely significant differences in the ratio of the $z$ values were observed between different species (ANOVA: $d f=5 ; F=7.116$; $p<0.01)$. This suggested that the two treatments of the wings have different effects on the DNA degradation for different species. The result was similar to Nagy's research [12]. For the folded and spread specimens of $D$. tabulaeformis, the distribution curves obtained based on our experimental results and the predicted distribution curves according to Equation (4) are shown (Figure 2). This figure visually demonstrates that the DNA degradation rate of folded specimens was lower than that of spread specimens.

Furthermore, the $u$ and $z$ values of the formalin-fixed larval specimens were smaller than those of the air-dried adult specimens (Supplementary Table 5). The average number of double-strand breaks per DNA of the formalin-fixed larval specimens was lower than that of the air-dried adult specimens and the percentage distribution of the DNA fragments was closer to that indicated by the random-breakage model. There were extremely significant differences in the ratio of the $u$ values (for formalin-fixed larval compared with the air-dried adult specimens) between different species (ANOVA: $d f=7 ; F=4.082$; $\mathrm{p}<0.01)$. Similarly, significant differences in the ratio of the $z$ values were observed between different species (ANOVA: $\mathrm{df}=7$; $F=3.476 ; p=0.02$ ). This suggested that the two preservation methods/moth stages have different effects on the DNA fragmentation of different species. For the formalinfixed larval and air-dried adult specimens of $D$. tabulaeformis, the distribution curve obtained based on our experimental results and the predicted distribution curve according to Equation 4 are shown in Figure 3. This figure visually demonstrates that the DNA degradation rate of formalinfixed larval specimens was lower than that of air-dried adult specimens.

\section{SUPPLEMENTARY DATA}

To view the supplementary data that accompany this paper please visit the journal website at: www.future-science. com/doi/suppl/10.2144/btn-2019-0166

\section{AUTHOR CONTRIBUTIONS}

$Y X U$ and HB Wang contributed to the experimental procedures, software, formal analysis and writing of the manuscript. $X Y$ Ren, M Wang and GH Li participated in the coordination of the work and provided resources.

\section{ACKNOWLEDGMENTS}

We would like to thank the staff of the specimen banks of forest insects at the Chinese Academy of Forestry for kindly providing the gypsy moth specimens. We would also like to thank the staff of the Key Laboratory of Forest Protection Lab for their help and useful suggestions.

\section{FINANCIAL \& COMPETING INTERESTS DISCLOSURE}

This study was supported financially by the Fundamental Research Funds for the Central Non-profit Research Institution of CAF (CAFYBB2017ZE002). The authors have no other relevant affiliations or financial involvement with any organization or entity with a financial interest in or financial conflict with the subject matter or materials discussed in the manuscript apart from those disclosed.

No writing assistance was utilized in the production of this manuscript.

\section{OPEN ACCESS}

This work is licensed under the AttributionNonCommercial-NoDerivatives 4.0 Unported License. To view a copy of this license, visit http://creativecommons.org/licenses/ by-nc-nd/4.0/ 


\section{REFERENCES}

Papers of special note have been highlighted as: • of interest

1. Lister AM. Natural history collections as sources of long-term data sets. Trends Ecol. Evol. 26(4), 150-154 (2011).

2. Holmes MW, Hammond TT, Wogan GO et al. Natural history collections as windows on evolutionary processes. Mol. Ecol. 25(4), 864-881 (2016).

- Reviews the prospects of specimens in evolutionary research. Evolutionary biology will be my main research direction in the future.

3. Harper GL, Maclean N, Goulson D. Analysis of museum specimens suggests extreme genetic drift in the adonis blue butterfly (Polyommatus bellargus). Biol. J. Linn. Soc. 88(3), 447-452 (2006)

4. Xu Y, Zhang $S$, Wang $H$, Wang $M$, Li G. Mitochondrial gene sequence (COI) reveals the genetic structure and demographic history of Lymantria dispar (Lepidopdemographic history of Lymantria dispar (Lepidoptera: erebidae: Lymantrinae) in
Insects 10(5), 146-165 (2019).

- Vividly presents an example. Specimens can be used in species identification as well as population genetic studies.

5. Krehenwinkel H, Pekar S. An analysis of factors affecting genotyping success from museum specimens reveals an increase of genetic and morphological variation during a historical range expansion of a European spider. PLOS ONE 10(8), e0136337 (2015)

6. Mikheyev AS, Tin MM, Arora J, Seeley TD. Museum samples reveal rapid evolution by wild honey bees exposed to a novel parasite. Nat. Commun. 6, 7991 (2015).

7. Li W, Cong Q, Shen J et al. Genomes of skipper butterflies reveal extensive convergence of wing patterns. Proc. Natl Acad. Sci. USA 116(13), 6232-6237 (2019).

8. Rowley DL, Coddington JA, Gates MW, Norrbom RA, Ochoa R, Vandenberg NJ. Vouchering DNA-barcoded specimens: test of a nondestructive extraction protocol for terrestrial arthropods. Mol. Ecol. Notes 7(6), 915-924 (2007)

9. Nagy ZT, Breman FC, DallAsta U. DNA barcoding of museum specimens of Lymantriidae preserved in th Royal Museum for Central Africa. Entomol. Rom. 15, 11-16 (2010).

- Supports a part of our results.

10. Shokralla S, Zhou X, Janzen DH et al. Pyrosequencing for mini-barcoding of fresh and old museum specimens. PLOS ONE 6(7), e21252 (2011).

11. Hernández-Triana LM, Prosser SW, Rodríguez-Perez MA, Chaverri LG, Hebert PD, Gregory TR. Recovery of DNA barcodes from blackfly museum specimens (Diptera: simuliidae) using primer sets that target a variety of sequence lengths. Mol. Ecol. Resour. 14(3), 508-518 (2014).

12. Price BW, Henry CS, Hall AC, Mochizuki A, Duelli $P$ Brooks SJ. Singing from the grave: DNA from a 180 -year old type specimen confirms the identity of Chrysoperla carnea (Stephens). PLOS ONE 10(4), e0121127 (2015).

13. Zimmermann J, Hajibabaei M, Blackburn DC et al. DNA damage in preserved specimens and tissue samples: molecular assessment. Front. Zool. 5(1), 1-13 (2008).

- Also investigates the effect of specimen storage time on DNA degradation, which has provided us with inspiration.

14. Miller JA, Beentjes KK, Helsdingen P, ljland S. Which specimens from a museum collection will yield DNA barcodes? A time series study of spiders in alcohol. Zookeys 365, 245-261 (2013).

15. Sproul JS, Maddison DR. Sequencing historical specimens: successful preparation of small specimens with low amounts of degraded DNA. Mol. Ecol. Resour. 17(6) 1183-1201 (2017).

- Provides methods for obtaining gene sequences from degraded specimens.

16. Wandeler P, Smith S, Morin PA, Pettifor R, Funk SM. Patterns of nuclear DNA degeneration over time - a case study in historic teeth samples. Mol. Ecol. 12(4), 1087-1093 (2003)

17. Erkens RHJ, Cross H, Maas JW, Hoenselaar K, Chatrou LW. Assessment of age and greenness of herbarium specimens as predictors for successful extraction and amplification of DNA. Blumea 53(2), 407-428 (2008).

18. Strange JP, Knoblett J, Griswold T. DNA amplification from pin-mounted bumble bees (Bombus) in a museum collection: effects of fragment size and specimen age on successful PCR. Apidologie 40(2), 134-139 (2009).

19. Sutrisno $H$. The impact of storage times of museum insect specimens on PCR success: case study on moth collections in Indonesia. J. Biosci. 19(2), 99-104 (2012).

20. Shedlock AM, Haygood MG, Pietsch TW, Bentzen P. Enhanced DNA extraction and PCR amplification of mitochondrial genes from formalin-fixed museum specimens. Biotechniques 22(3), 394-396 398, 400 (1997).

21. Heintzman PD, Elias SA, Moore K, Paszkiewicz K, Barnes I. Characterizing DNA preservation in degraded specimens of Amara alpina (Carabidae: coleoptera). Mol. Ecol. Resour. 14, 606-615 (2014)

- Provides studies about DNA preservation in degraded specimens that may guide the processing, storage and selection of specimens.

22. Hajibabaei M, Smith MA, Janzen DH, Rodriguez JJ, Whitfield JB, Hebert PDN. A minimalist barcode can identify a specimen whose DNA is degraded. Mol. Ecol. 6(4), 959-964 (2006)

23. Hajibabaei M, Janzen DH, Burns JM, Hallwachs $W$ Hebert PDN. DNA barcodes distinguish species of tropical Lepidoptera. Proc. Natl Acad. Sci. USA 103(4), 968-971 (2006).

24. Wu S, Pa FM. Statistical inference of qualitative data. In SPSS Statistical Analysis. Wu S, Pa FM, Xia ZY (Eds). Tsinghua University Press, Beijing, China, 115-117 (2014)

25. Cook VE, Mortimer RK. A quantitative model of DNA fragments generated by ionizing radiation, and possible experimental applications. Radiat. Res. 125(1), 102-106 (1991).

26. Hu ZZ, Huang J, Wang ZH. Summary on DNA extraction of insect specimens preserved in collections. Wuyi. Sci. J. 29, 166-169 (2013).

- Extraction of specimen DNA is a very important step for further research.

27. Pang GF, Zhang YP. Progress of old sample DNA study. Zool. Res. 22(6), 490-496 (2001).

28. Xu GY, Chen B, Wu WW, Liu YQ, Lu C. DNA extraction of museum specimens and RAPD-PCR reaction of longicorn beetles. J. Southwest Agr. U. 25(2), 95-98 (2003).

29. Burrell AS, Disotell TR, Bergey CM. The use of museum specimens with high-throughput DNA sequencers. $J$. Hum. Evol. 79, 35-44 (2015).

30. Dodsworth S. Genome skimming for next-generation biodiversity analysis. Trends Plant Sci. 20(9), 525-527 (2015).

31. Zhang YC, Zheng ZM. RAPD analysis of genomic DNA specimens of dry coccinellid specimens. J. Northwest U. 29(6), 581-583 (1999).

32. Prosser SWJ, DeWaard JR, Miller SE, Hebert PDN. DNA barcodes from century-old type specimens using next-generation sequencing. Mol. Ecol. Resour. 16(2), 487-497 (2016).

33. Tin MYM, Economo PE, Mikheyev AS. Sequencing degraded DNA from non-destructively sampled museum specimens for rad-tagging and low-coverage shotgun phylogenetics. PLOS ONE 9(5), e96793 (2014).
pheriment

34. Besnard G, Bertrand SAT, Delahaie B, Bourgeois YXC, Lhuillier $E$, Thébaud $C$. Valuing museum specimens high-throughput DNA sequencing on historical collections of New Guinea crowned pigeons (Goura). Biol. $J$. Linn. Soc. 117(1), 71-82 (2016).

- The successful application of next-generation sequencing technology in specimen sequencing will reveal a large amount of genetic information.

35. Zhang SM, Zhang Z, Wang HB, Chi DF. Comparative analysis on methods for genomic DNA extraction of Ips typographus L. J. Anhui. Agr. Sci. 37(13), 5883-5885 (2009)

36. Xia YZ, Sheng Y, Chen YY. Influence of formalin on DNA extraction and amplification from fixed specimens. Sichuan J. Zool. 25(3), 662-665 (2006). 